\title{
Clinch-bonded hybrid joining for similar and dissimilar copper alloy, aluminium alloy and galvanised steel sheets
}

\author{
Lei $\mathrm{Lei}^{1)}$, Xiaocong $\mathrm{He}^{1), *}$, Desuo Zhao ${ }^{1)}$, Yue Zhang ${ }^{1)}$, Fengshou $\mathrm{Gu}^{2)}$, Andrew Ball ${ }^{2)}$ \\ 1) Innovative Manufacturing Research Centre, Kunming University of Science and Technology, \\ Kunming, 650500, P. R. China \\ 2) Centre for Efficiency and Performance Engineering, University of Huddersfield, Queensgate, \\ Huddersfield, HD1 3DH, UK.
}

\begin{abstract}
Clinch-bonded hybrid joining technology has been applied increasingly in different manufacturing disciplines. In this study, specimens of both similar and dissimilar sheets of H62 copper alloy, aluminium alloy and galvanised steel sheets were prepared in single-lap and T-joints. Tensile-shear tests and peeling tests were carried out for studying the load-bearing capacity and energy absorption of different clinch-bonded hybrid joints. The failure fractures were studied by a scanning electron microscope to characterise the different failure modes. Results show that the shear strength of the specimens, which results mainly from the adhesive, is better than their peeling strength, which is closely related to clinched structures. The mixed neck fracture exhibited the highest shear strength, and a better ability to absorb energy could be obtained by decreasing the material strength of the lower sheets in the tensile-shear test. In the peeling test, it was found that the best energy absorption ability could be achieved by the failure mode of upper sheet tearing, and improving the strength of the lower sheets resulted in greater joint peeling strength.
\end{abstract}

Key words: clinch-bonded hybrid joining; load-bearing capacity; energy absorption; failure mode; scanning electron microscope.

\footnotetext{
*Corresponding author: Tel. : +86-871-65930928

E-mail address: x_he@kmust.edu.cn
} 


\section{Introduction}

In the present manufacturing engineering industry, a variety of metallic materials are used to satisfy the different working environments and requirements. Copper and copper alloys, which possess excellent electric and thermal conductivity, good process forming, and corrosion resistance, are widely used in industrial fields such as electronic engineering and mechanical manufacturing [1]. Along with rapid industrial development, as well as increasingly severe energy and environmental problems, lightweight becomes a matter of concern in designing and manufacturing process. Aluminium alloys characterises low density and high strength, and it has easy access to lightweight [2]. Because of its low cost and reliable performance, steel constitutes a large proportion of industrial materials used in the world even today [3]. Nowadays, these metals are largely chosen for use in aerospace and automotive engineering, as well as other manufacturing disciplines. To enable the reliable joining of materials, and to make full use of the excellent properties of dissimilar materials, it is necessary to research material joining of dissimilar sheets.

Welding is nowadays the most widely used method of joining metal, and is successfully applied for joining similar metals. However, the welding of dissimilar metal materials could lead to welding defects, resulting from significant differences in physical and chemical properties, and reducing the comprehensive properties of joints. With the development of material-joining technology, some new methods, such as self-piercing riveting (SPR), adhesively bonding and clinching with no pollution issues, low energy requirements, and high efficiency have emerged [4-6].

Clinching has rapidly developed into a new type of mechanical joining technique, used in the automotive and aerospace industries, over the last thirty years [7, 8]. The failure mode of clinched joints determined by tensile-shear tests, and the influence of clinching-process parameters on joints, were studied by Varis [9, 10]. Oudjene et al. [11, 12] improved the strength of clinched joints by changing the geometrical shape, and also optimised die parameters by using the least square method and the response surface analysis. In the study of Paula et al. [13], the influence of technological parameters on clinching moulding and static strength were explored, and the distribution of stress in plastic deformation areas was observed from a microscopic perspective. Lee et al. [14, 15] established an intensity model of a tensile-shear test for clinched joints based on die geometrical parameters, and then researched its influence on clinched properties of dissimilar sheets of aluminium and steel. The stress state of clinched interlock structures under tensile and shear forces was analysed by Mucha et al. [16, 17, 18], who also compared the strength of clinching with that of spot welding. The clinching process parameters optimization using finite element (FE) simulations is continuously developing. The finite element method was applied for the assessment of punch load in the clinching process $[19,20,21]$. The die wear experimental data were compared with the results of FEA numerical simulation, which substantiated the fact that the dominant part of wear is localized in the radius area surrounding the die cavity [22]. The application of X-ray micro-diffraction to study 
the local changes in austenite content in clinching joints was presented by Krzton et al [23]. The effects of blank holder geometric parameters and forming forces on the formed shape of the interlock in clinching were studied in different temper conditions [24]. Coppieters et al [25] presented an analytical approach to estimate the pull-out strength of clinching joint though a new experimental setup and a FE model. The clinched joint of cold rolled steel was tested at different fatigue loads by Kim [26], and the results showed that the load amplitude, which reached the fatigue limit of 2.5 million cycles, was $50 \%$ of the static load stress.

Mori and colleagues [27, 28] compared the fatigue properties of spot welding, SPR and clinching, and found that the fatigue properties of SPR and clinching were better than that of spot welding. Lambiase and colleagues [29-32] explored the influence of extensible die clinched-process parameters on joints' structures. They also reduced moulding stresses, and improved the clinching joining property of AA6082T6 aluminium alloy by a variety of methods: reducing depth of the lower die, preheating treatment, and changing the shape of the punch. Jayasekara et al. [33] analysed the influence of die parameters on joint-moulding quality, and considered elastic-plastic, rigid-plastic, and Coulomb friction in FE analyses. Chen et al. [34-39] investigated a new clinching reshaping method, by using a pair of flat and bumped die to reduce the button height, a flat surface can be created by the improved clinching process to increase the joint strength of clinching. Besides, a compressing technology was investigated with experimental method.

Adhesion as a joining technique progressed rapidly with the development of high strength adhesives in recent years. Ojalvo and Eidinoff [40] studied the stress distribution of single-lap adhesive joints with different adhesive-layer thicknesses, and also introduced G-R theory to extend basic calculation methods of joints. The stress singularity order was solved using a FE method by Van Tooren and Krakers [41]. The singularity index shows the shape of singularity stress field, and analyses the stress intensity factor which expresses the size of the stress field. Apalak et al. [42] used three-dimensional (3D) FE analysis and back-propagation artificial neural networks to study the 3D free-vibration performance of adhesive joints. The natural frequency, vibration mode, and frequency response function of single-lap adhesive joints in cantilever beam structures were studied systematically [43-45].

Clinching is a specific technology that does not use rivets, and whose cost and weight are significantly lower than SPR and traditional riveting, especially used in large-scale applications. However, its static strength is relatively low. With adhesion, stress concentration is efficiently avoided to acquire better strength and higher fatigue resistance, due to surface-to-surface contact. As a result of adhesives' high sensitivity to temperature and humidity, the joints failures could occur in an instant, leading to potential safety hazards. In order to avoid adhesive failure resulting from the 
environment, and improve the strength of clinched joints, a new mechanical-joining technology, combining adhesion and clinching, has been proposed, the so-called clinch-bonded hybrid joining [46, 47].

A few studies on clinch-bonded hybrid joining have been carried out since its inception, and these focused primarily on the origins, including technological processes, energy absorption, and strength factors. The joining properties of SPR, welding, and clinch-bonded hybrid joints were compared by Moroni et al. [46]. They highlighted the obvious superiority of clinch-bonded hybrid joints on joining strength and energy absorption. Single-lap joints were prepared with special processing, where the adhesive layer solidified before clinching, and then tensile-shear tests were carried out by Balawender et al. [48], who believe that adhesives play an important role in the joining strength of clinch-bonded hybrids. Lee et al. [49] analysed the properties of clinch-bonded hybrids on aluminium alloy sheets by using a cohesive zone model, and certified the feasibility in a practical application. Based on multi-objective optimisation, the technological process of clinch-bonded hybrid joints with dissimilar sheets of steel and aluminium alloy was presented by Chen et al. [50], who also reported that clinch-bonded hybrids double the joining strength of clinched joints. From the study of $\mathrm{He}$ [51], we can see that he comprehensively reviewed clinching techniques including tool design, join-ability of lightweight sheets, hybrid and modified clinching processes. The failure loads and modes for three types of joints: adhesive bonding, bolt fastening and adhesive-bolt hybrid joining were compared by Kweon et al [52], and it was found that hybrid joining improves joint strength when the mechanical fastening is stronger than the bonding. When the strength of the bolted joint is lower than that of the bonded joint, bolt joining contributes little to the strength of the hybrid joint.

In conclusion, the research of clinching and adhesion joining technology, including processing parameters, mechanical properties, and reference discussions, has been comprehensively conducted. For clinch-bonded hybrid joining, previous publications mainly discussed the preliminary technology with single-lap sheets, and focussed primarily on traditional material joining in similar configurations. In present study, specimens of clinch-bonded hybrid joints with similar sheets of H62 copper alloy and dissimilar sheets of H62 copper alloy with A15052 aluminium alloy and galvanised steel were prepared and two types of joints, single-lap joints for shear strength and T-joints for peel strength, were manufactured with all combinations of sheets. The mechanical properties of the joints were comprehensively evaluated by analysing joint loads, energy absorption values, and failure modes, in the two types of joints. 


\section{Specimen preparation}

\subsection{Materials and specimen configuration}

The sheet materials used in this study were H62 copper alloy, Al5052 aluminium alloy, and Q215 galvanised steel with $1.5 \mathrm{~mm}$ thickness. According to GB/T 228-2002 Indoor tensile testing of metallic materials, the material performance test, using an MTS Landmark Servo-hydraulic Test System, were conducted to obtain their mechanical properties with extensometer gauge length of $20 \mathrm{~mm}$ and elongation rate of $2 \mathrm{~mm} / \mathrm{min}$. The results are presented in Table. 1 . The stress-strain curves are showed in Fig.1.

Table. 1 Mechanical properties of sheet materials

\begin{tabular}{ccccc}
\hline Materials & $\begin{array}{c}\text { Young's Modulus } \\
(\mathrm{GPa})\end{array}$ & $\begin{array}{c}\text { Tensile strength } \\
(\mathrm{MPa})\end{array}$ & $\begin{array}{c}\text { Yield strength } \\
(\mathrm{MPa})\end{array}$ & $\begin{array}{c}\text { Elongation } \\
(\%)\end{array}$ \\
\hline H62 & 110 & 424.5 & 340.3 & 30 \\
A15052 & 69.5 & 229.9 & 211.5 & 12 \\
Q215 Galvanised Steel & 191 & 365.6 & 337.8 & 32.7 \\
\hline
\end{tabular}

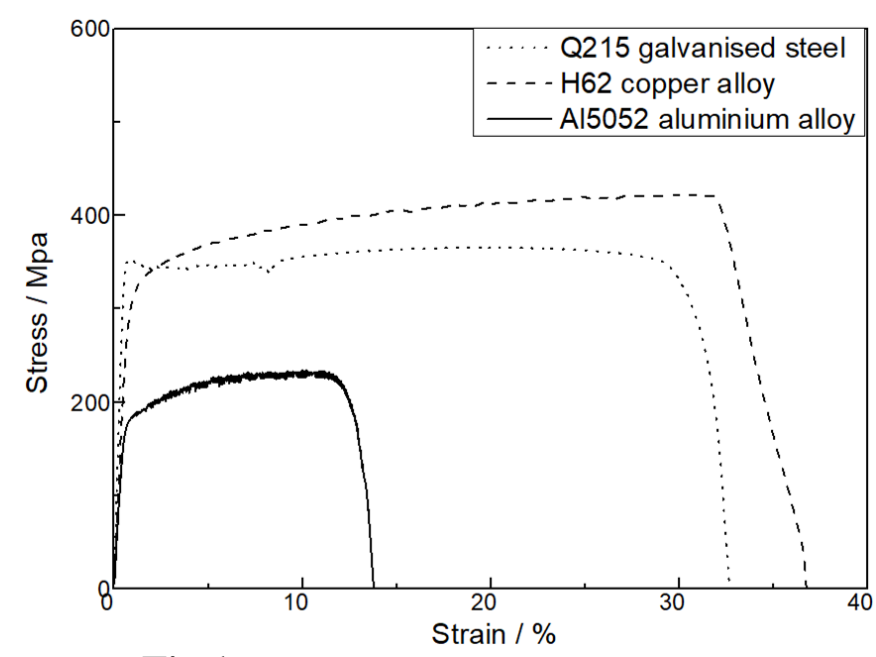

Fig.1. Stress-strain curves of sheet materials

To obtain better joint strengths in clinched joints with dissimilar sheets, it is widely accepted that the sheet with the greater strength is regarded as the upper sheet, and the sheet with the lower strength will be the lower sheet. The upper sheet with greater strength can embed and flow adequately into the lower sheet with lower strength under punch pressure because of material strength difference, which means that the joint could form sufficient plastic deformation and provide greater mechanical-interlock force during the tensile-shear and peeling tests. From Table 1, the upper and lower sheets can be identified, and the nomenclature used in this paper is defined in Table 2. 
Table. 2 Combination of the specimens

\begin{tabular}{ccccc}
\hline Nomenclature & Upper sheet & Lower sheet & Thickness & Configuration of specimens \\
\hline LHH & H62 copper alloy & H62 copper alloy & $1.5 \mathrm{~mm}$ & Single-lap joints \\
LHA & H62 copper alloy & Al5052 aluminium alloy & $1.5 \mathrm{~mm}$ & Single-lap joints \\
LHS & H62 copper alloy & Galvanised steel & $1.5 \mathrm{~mm}$ & Single-lap joints \\
PHH & H62 copper alloy & H62 copper alloy & $1.5 \mathrm{~mm}$ & T-joints \\
PHA & H62 copper alloy & Al5052 aluminium alloy & $1.5 \mathrm{~mm}$ & T-joints \\
PHS & H62 copper alloy & Galvanised steel & $1.5 \mathrm{~mm}$ & T-joints \\
\hline
\end{tabular}

Two types of joints, single-lap joints for shear testing and T-joints for peeling testing, were prepared with 8 specimens for each sheet configuration. Single-lap joints and T-joints comprised an upper sheet and a lower sheet, as shown in Fig. 2.

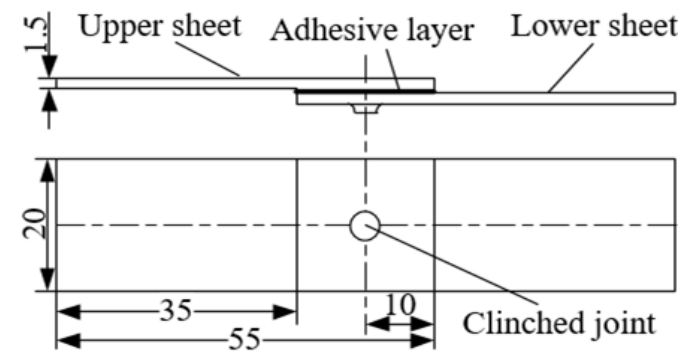

(a) Single-lap joint

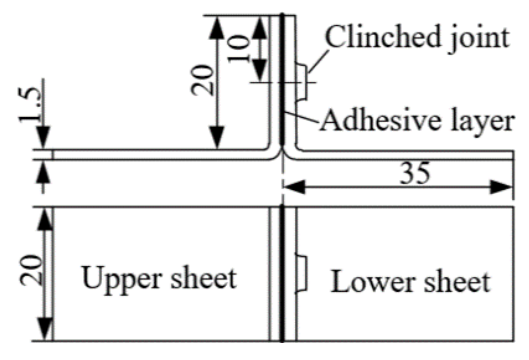

(b) T-joint

Fig.2. Configuration of specimens: (a) Single-lap joint, (b) T-joint

\subsection{Technological process}

The process of clinch-bonded hybrid joining is shown in Fig. 3. The sheets' surfaces were first polished with abrasive paper and degreased using anhydrous ethanol, then dried. Secondly, acrylic low-odour adhesive DP430, used in this study, present high shear strength, good water resistance and chemical resistance. The adhesive was spread on the sheet surfaces with $0.2 \mathrm{~mm}$ layer thickness and a bonding area of $20 \mathrm{~mm} \times 20 \mathrm{~mm}$. Thirdly, the bonding area of the upper and lower sheets were placed over each other as shown in Fig. 3, and clinched using a RIVCLINCH 1106 P50 clinching machine immediately. The clinching machine and extensible die clinching tools are shown in Fig. 4. The clinch-bonded hybrid joint forming test carried out in 20 s for a specimen and the specimens were then allowed to solidify for $24 \mathrm{~h}$.

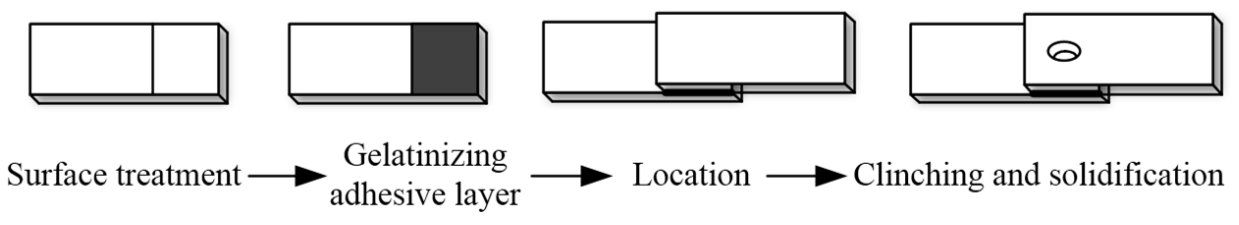

Fig. 3. Technological process of clinch-bonded hybrid joining 


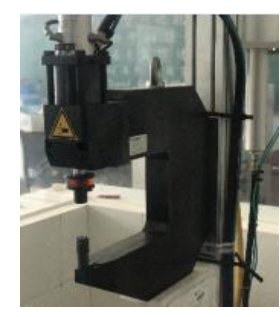

(a) Clinching machine

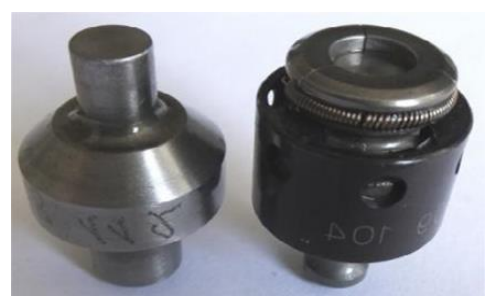

(b) punch model and extensible die tool

Fig. 4. Clinching machine and clinching tools

The tool geometry parameters of clinching forming used in present study were the same, the punch model chose SR5207 and extensible die clinching tool was SR60310. Besides, the punch pressure remained at $0.6 \mathrm{MPa}$.

\subsection{Quality assessment of joints}

During the clinching process, the upper sheet was punched into the lower sheet, and underwent plastic deformation to form a mechanical interlock as shown in Fig. 5. The difference of materials combinations correspond to different cross-sections under the same punch pressure and tool parameters. The strength of clinched joints depends mainly on three cross-sections: the button thickness $(\mathrm{X})$, the neck thickness $\left(\mathrm{t}_{\mathrm{N}}\right)$, and the produced undercut $\left(\mathrm{t}_{\mathrm{U}}\right)$. The three important cross-sections were observed and measured by cutting the half of joint. In present study, $t_{N}$ and $t_{U}$ were measured because of their decisive effect on the failure modes of joint.

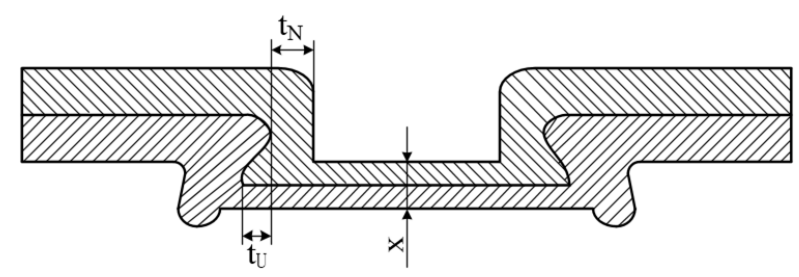

Fig. 5. Quality assessment criteria of the clinched joint

The use of adhesives in clinch-bonded hybrid joining improves the joining strength of the adhesion area, and has little effect on the clinched structure. Therefore, the strength provided by clinching could be observed and deduced by the cross-sectional structure of the clinch-bonded hybrid joining.

Additionally, the difference between a single-lap joint and a T-joint is primarily in the configuration of the specimens, as they have the same cross-sectional parameters for the same material combinations. For this study, the cross-section parameters selected for LHH, LHA, and LHS, are shown in Fig. 6. In the LHA joint, the neck thickness $t_{\mathrm{N}}$ is $0.58 \mathrm{~mm}$ and the undercut $\mathrm{t}_{\mathrm{U}}$ is 0.31 
mm. Similarly, $t_{N}=0.39 \mathrm{~mm}$ and $t_{U}=0.32 \mathrm{~mm}$ in the LHS joint, and $t_{N}=0.56 \mathrm{~mm}$ and $t_{U}=0.13 \mathrm{~mm}$ in the LHH joint.

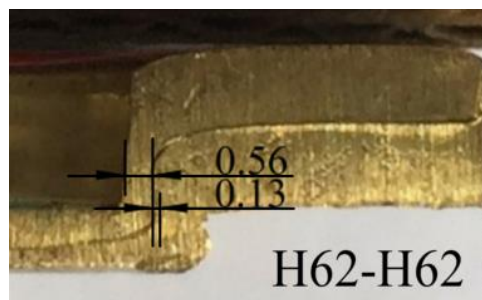

(a) $\mathrm{LHH}$

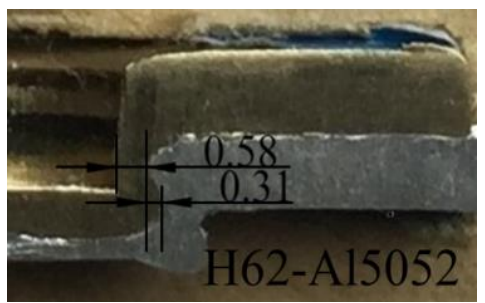

(b) LHA

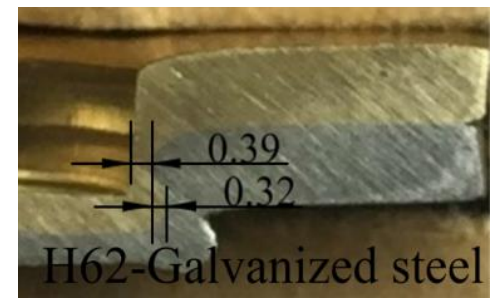

(c) LHS

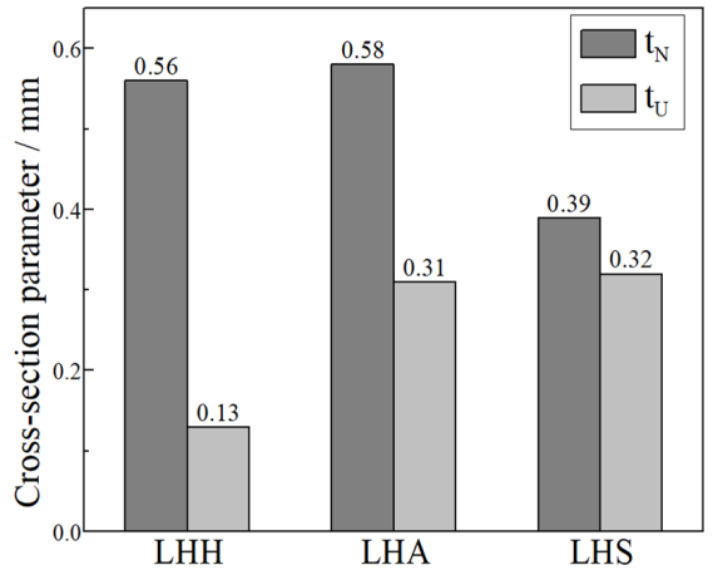

(d) Parameters comparison of three groups

Fig. 6. Cross-section parameters of clinch-bonded hybrid joints

By comparing the produced undercuts $\left(t_{U}\right)$ of the above joints, it can be seen that $t_{U}$ of both the LHA and LHS is relatively large because of their good mechanical interlock structures, which means that their joints could provide greater mechanical interlock forces during the tensile-shear and peeling tests. However, the upper sheet of the LHH was not adequately embedded in the lower copper sheet to form sufficient deformation. Therefore, it presented a relatively short $t_{U}$, and its joint readily experienced button-separation failure in both the tensile-shear and peeling tests. The reason for the difference is that the hardness of aluminium and galvanised steel, as the lower sheet, is lower than that of copper alloy upper sheet. As a result, the upper sheet can flow sufficiently into the lower sheet, causing plastic deformation and forming a good mechanical interlock structure.

Likewise, the larger $t_{\mathrm{N}}$ of the LHA and LHH groups can clearly be seen by comparing the produced neck thickness of the three groups, showing that they could withstand greater shear forces. However, the LHS joint is prone to suffer neck fracture failure at the same shear force as a result of the smaller neck thickness.

\section{Experiment}

\subsection{Tensile-shear test}


Tensile-shear tests were conducted by an MTS Landmark Servohydraulic Test System to characterise the mechanical properties of the different single-lap joints. The end of upper sheet was clamped, and a quasi-static downward displacement load was applied to the end of the lower sheet. The tensile-shear test was performed at a constant displacement rate of $10 \mathrm{~mm} / \mathrm{min}$, and terminated when the specimen separated, or the load decreased by $90 \%$ of the ultimate force. Two spacers, with the same thickness as the sheets, were added on either end of specimens in order to reduce the impact of additional bending during the tensile-shear test of the single-lap.

\subsection{Peeling test}

A peeling test was carried out with the MTS Landmark Servohydraulic Test System to determine the peeling properties of the different joints. The end of the upper sheet of the T-joint was fixed, and a quasi-static downward displacement load was applied to the end of lower sheet. The peeling test used the same displacement rate of $10 \mathrm{~mm} / \mathrm{min}$ and terminal conditions as the tensile-shear test.

\subsection{Scanning electron microscope analysis}

Different joint-failure modes were evaluated by tensile-shear and peeling tests. The typical failure fractures were studied by a Czech TESCAN scanning electron microscope (SEM) to analyse the failure mechanisms.

\section{Experiment results}

\subsection{Tensile-shear test results}

The results were evaluated by using the Lilliefors test for normal distribution, and the Matlab normfit parameter-estimation function, with a 95\% confidence level in each group. The results show that the mean and standard deviation of the experimental results met the requirements of the confidence interval, indicating that the data is valid. The load-displacement curves of the three groups of single-lap joints are shown in Fig. 7.

As can be seen in Fig. 7, the load-displacement curves showed the same linear trend, caused by elastic deformation of the sheet, during the initial stretching. As the load increased, the curves gradually rose smoothly upwards to the maximum shear strength, provided by the adhesive and the clinched structure. When the adhesive started to peel from the sheet, which is bonding shear failure, the curves fell rapidly. At this point, the joint shear strength was maintained by the clinched structure. The curves, after decreasing, rebounded to a certain degree. After this, the three groups of load-displacement curves displayed different failure trends. 
The LHH group had not formed an effective mechanical interlock structure, and the neck was pulled out from the side of the clinched structure when the mechanical interlock force was less than the load. As the tensile displacement increased, the neck material showed some plastic deformation, and the joint neck became smooth until it was fully pulled out. The upper and lower sheets separated, by a button separation failure mode, and slight scratching was noted.

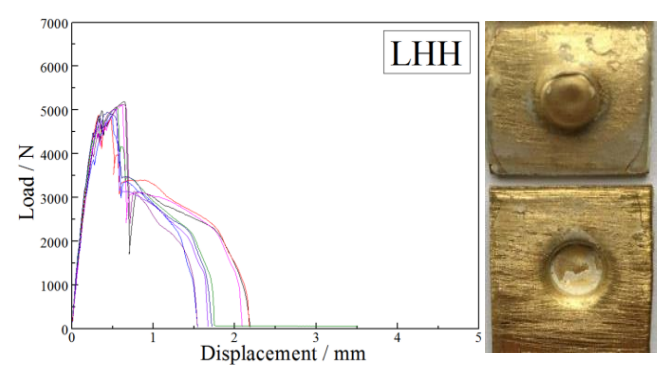

(a) H62-H62

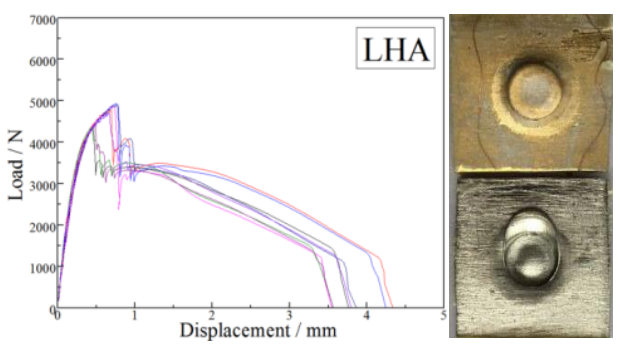

(b) H62-A15052

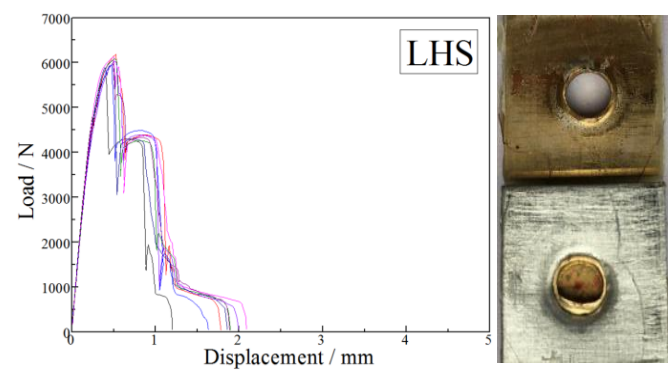

(c) H62-Galvanized steel

Fig. 7. Load-displacement curves and failure modes of different single-lap joints

As for the LHA group, the upper and lower sheets had to incur a certain amount of plastic deformation to destroy the fine interlock structure after the adhesive failed. It can be seen from Table 1 , that the material strength of aluminium alloy as the lower sheet is lower than that of the upper sheet copper alloy. Therefore, when the tensile load reached the yield strength of the lower sheet, the lower sheet was deformed and pushed outwards by the upper sheet, to form a deposit, as shown in Fig. 7. As the tensile displacement continued to increase, the load was first absorbed by plastic deformation, and then gradually decreased. The upper sheet was gradually sheared out from the clinched lower sheet, with significant plastic deformation.

Similarly, the effective mechanical interlock structure of the LHS group was broken in the early stages of the tensile load being applied. The first plateau in the load-displacement curve occurred as the upper sheet was being pulled out from the side of the clinched structure. According to the joint cross-section parameters, the $\mathrm{t}_{\mathrm{N}}$ of the LHS group was relatively small, and the neck was the weakest part for bearing the shear force. As the load increased, a crack appeared in the thinnest part of the 
neck, when the mechanical-interlock strength was greater than the neck tensile strength of the upper sheet. The joint load then decreased rapidly, and the entire neck began to tear. The second plateau on the curve ended when the neck was completely fractured, and the upper and lower sheets separated.

The energy absorption value is a comprehensive parameter, reflecting the bearing capacity and tensile displacement of a joint. Its value can be represented by the area enclosed by the load-displacement curve and the X-axis. Fig. 8 (a) shows the mean failure load of three groups' joints, and Fig. 8 (b) shows a comparison of the energy absorption value of the three groups, generated by the Matlab R2014b numerical computation method.

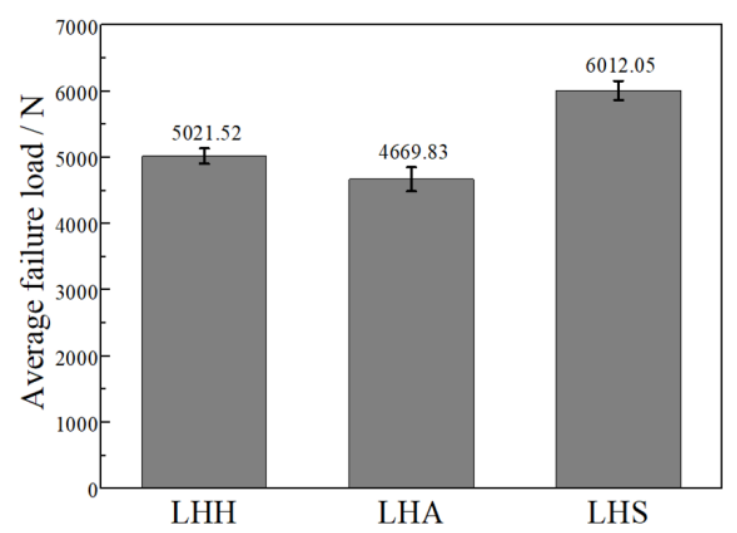

(a) Failure load of three groups

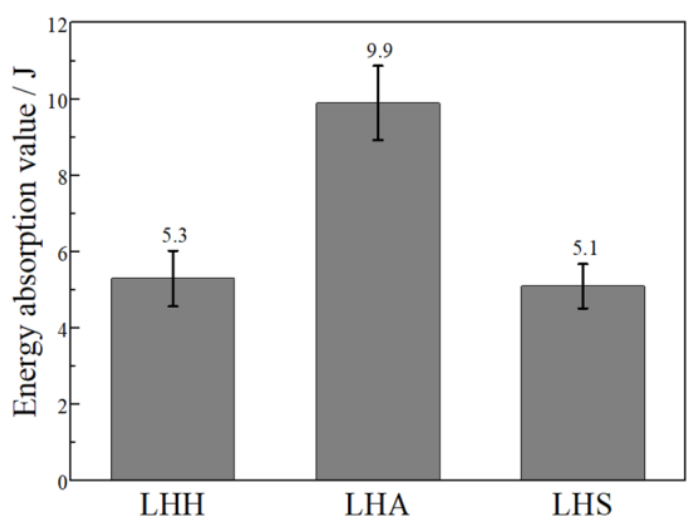

(b) Energy absorption value of three groups

Fig. 8. Result of tensile-shear test for different single-lap joints

It can be seen from Fig. 8 that the failure load of the LHH group is $5021.52 \mathrm{~N}$, and its energy absorption value is average. The LHA group has the lowest failure load of $4669.83 \mathrm{~N}$, but the joint has evident plastic deformation with long tensile displacement, resulting in a fuller load-displacement curve for the best ability to absorb energy. The failure load of the LHS group is $6012.05 \mathrm{~N}$, the highest of the three groups, but its neck fractures rapidly, resulting in its average energy absorption ability.

In conclusion, mixed neck fractures exhibit the best shear strength, and a better ability to absorb energy could be obtained by decreasing the material strength of the lower sheet in the tensile-shear test.

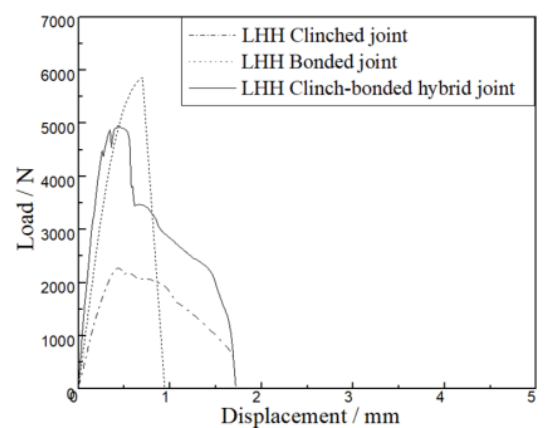

(a) $\mathrm{LHH}$

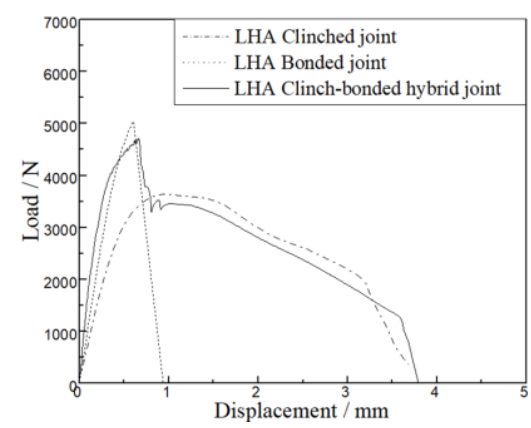

(b) LHA

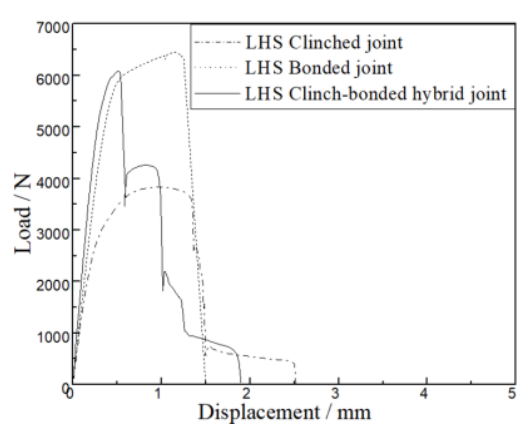

(c) LHS

Fig. 9. Load-displacement curves of clinched joint, bonded joint and clinch-bonded joint 
Fig. 9 shows the contradistinction of load-displacement curves of clinched joint, bonded joint and clinch-bonded hybrid joint. It can be seen that for the tensile-shear test of LHH, LHA and LHS, clinching presents better ability to absorb energy owing to gradual failure process of clinched structure, yet lower failure load. Bonded joint has high shear strength but fails rapidly in an instant. the clinch-bonded hybrid joining combines the advantages of them to behave high failure load and good energy absorption ability.

Different joint failure modes of the LHH, LHA, and LHS groups were tested by the tensile-shear test, and typical failure fractures were studied by a Czech TESCAN SEM to analyse the failure mechanisms. The results are shown in Figs 10-12.

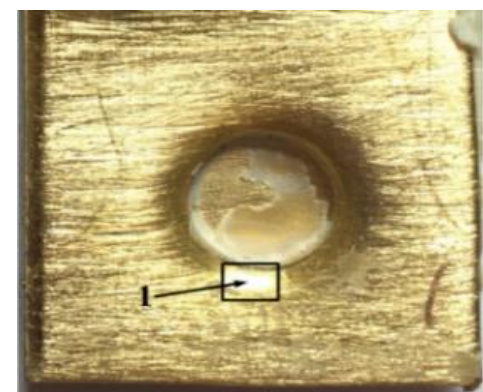

(a) Macroscopic profile

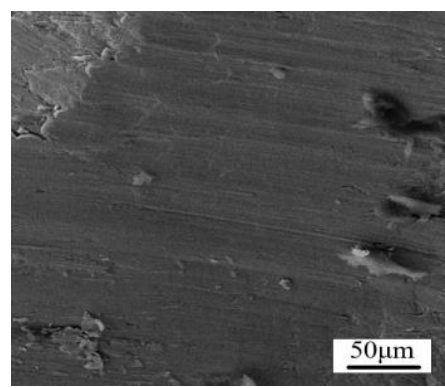

(b) Microcosmic profile in area 1

Fig. 10. Scratching of lower sheet of LHH joint

Fig. 10 shows the macroscopic and microscopic profiles of the LHH group. There was no obvious plastic deformation of the lower copper alloy sheet, and the entire clinched area retained its structural integrity, and was completely smooth except for a slight scratching mark in area 1. It can be seen from Fig. 10(b) that the microscopic profile of the scratching is a very thin stripe with a high distribution density. The surface is covered with some debris and oxides that are distributed in the same plane. Area 1 was subjected mainly to a slight compression force, and the direction of the scratching is the same as the direction of the shear force in the experiment.

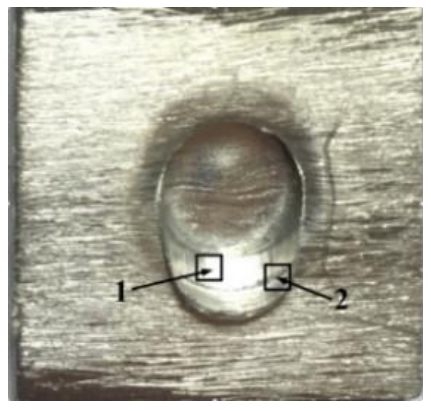

(a) Macroscopic profile

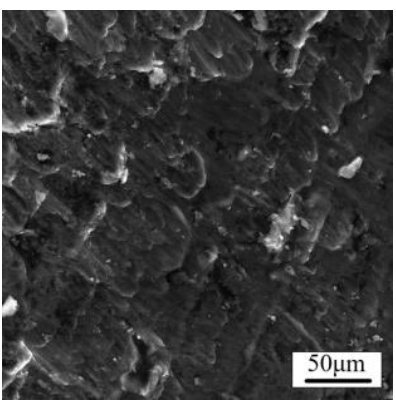

(b) Microcosmic profile in area 1

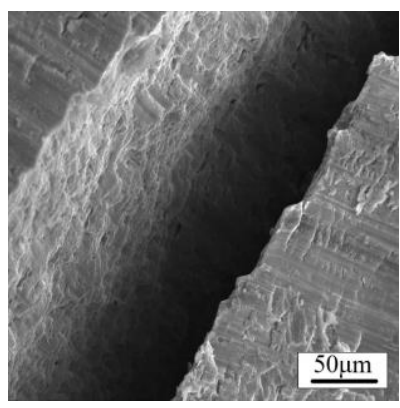

(c) Microcosmic profile in area 2

Fig. 11. Plastic deformation of lower sheet of LHA joint 
The lower aluminium alloy sheet with significant plastic deformation in the LHA group can be seen in Fig. 11. As shown in Fig 11(a), the material forced by the upper copper alloy sheet flowed outside to form a deposit at the end of the expansion, and a crack fracture is shown in area 2. When comparing to the stripe texture of the LHH group, there is stratification and numerous different-sized shallow pits on the fracture surface of the LHA group, the texture scratching is no longer obvious, the debris is significantly reduced, and the entire surface density shows a distinct increase. This indicates that the area suffered a larger compression force, and greater deformation, than the LHH group. It can be observed from Fig. 11(c) that a macroscopic longitudinal crack appeared in area 2 after intense material movement; the crack is not flush, and shows a rugged fracture, which is a ductile fracture.

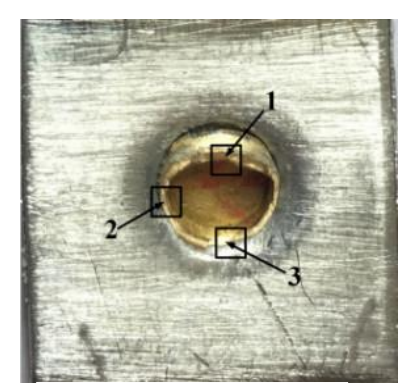

(a) Macroscopic profile

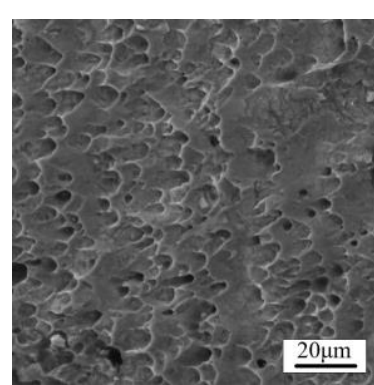

(b) Microcosmic profile in area 1

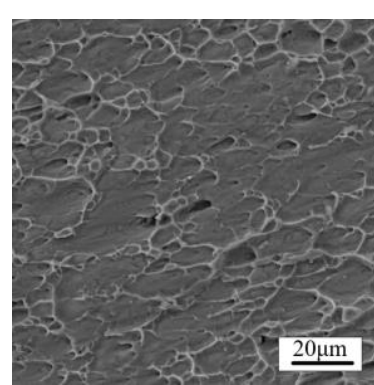

(c) Microcosmic profile in area 2

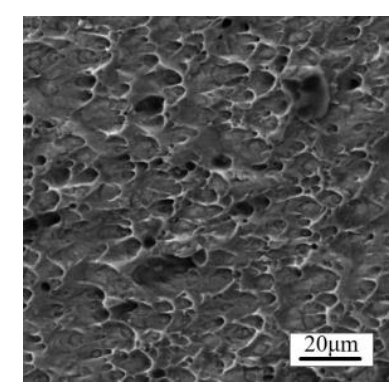

(d) Microcosmic profile in area 3

Fig.12. Mixed failure with neck fracture of upper sheet of LHS joint

Fig. 12 shows the neck fracture of the LHS group. It can be seen in Fig. 12(b) that a large number of elongated dimples, forming a shallow ' $U$ ' shape, appeared in the same direction in area 1 , and a small amount of microspore and the second phase of particles also appeared on the surface. Area 1 has typical ductile fracture characteristics, caused by microporous polymerization shear. Many high-density, short, and cured tearing ridge-lines are seen as typical small-river patterns in area 2, which is the quasi-cleavage fracture between the ductile and cleavage fractures. It can be seen from Fig. 12(d) that a mass of large, deep, elongated dimples surrounded by small dimples and large cavities, making the entire surface uneven, especially at the tearing edge of the cleavage. Area 3 is a mixture of ductile and cleavage fractures. Area 3 will absorb more energy before fracture because of the larger and deeper dimples, as opposed to areas 1 and 2. From the above observations, the fracture path of the LHS group is first to tear in area 1, spread through area 2, and completely fracture in area 3.

\subsection{Peeling test results}

The results were also evaluated by the Lilliefors test for normal distribution to guarantee valid 
load-displacement curves, as shown in Fig 13.

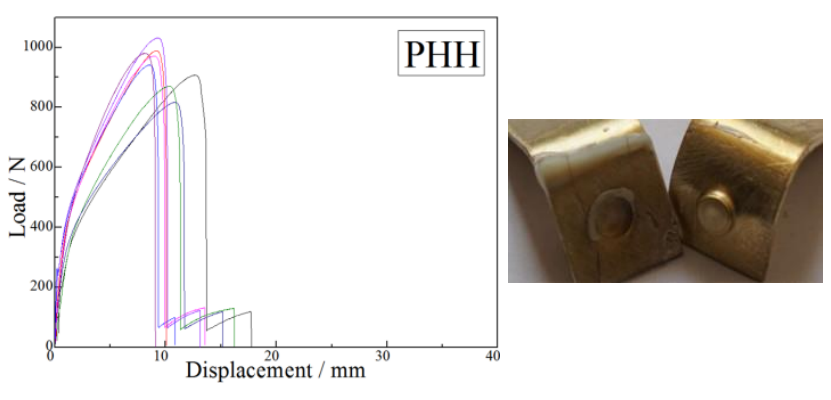

(a) H62-H62

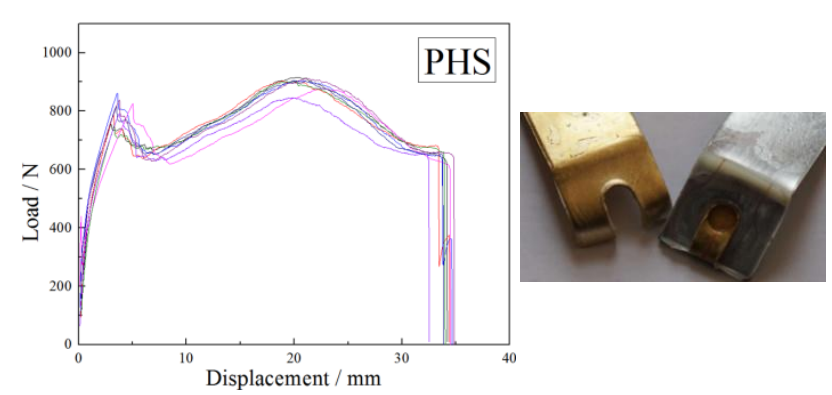

(b) H62-Galvanized steel

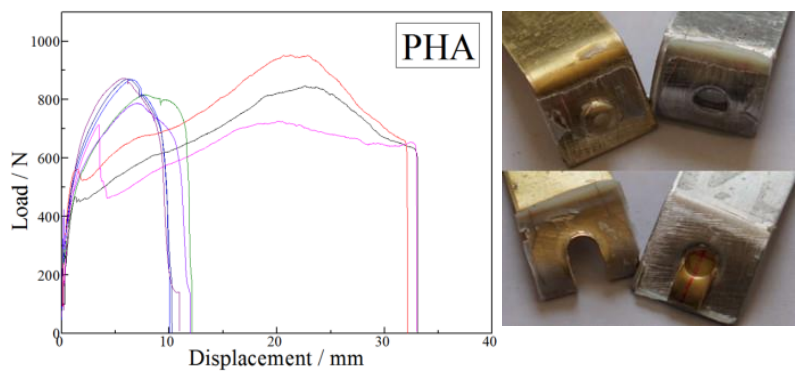

(c) H62-A15052

Fig. 13. Load-displacement curves and failure modes of different T-joints

Similarly, as can be seen in the initial stretching of the three groups of T-joints, the load rapidly increased with a slight increase in displacement, which is a result of the elastic deformation of the specimen material. The upper and lower sheets then began to deform plastically under the peeling force, which is perpendicular to the clinched surface. The load gradually increased to the maximum peeling strength provided by the combined adhesive and clinched structure. At the failure of the adhesive layer, the load-displacement curves fell abruptly, and the clinched structure began to bear the full peeling force. The three groups of curves all show different trends from that point.

After the failure of the adhesive, the joint load of the PHH group dropped to approximately 1000 $\mathrm{N}$, and showed only a modest recovery due to the clinched structure. However, the insufficient interlock force could not absorb the greater peeling strength, and the clinched structure failed after transient tensile displacement, and the load reduced to zero. The upper and lower sheets separated completely before any significant bending of the specimen occurred, and the angle was maintained at approximately $90^{\circ}$.

There were two types of failure modes in the peeling test of the PHA group. The first is similar to the PHH group, with button separation of a T-bending angle at nearly $90^{\circ}$. Compared to the $\mathrm{PHH}$ group, the combination of copper alloy and aluminium alloy is more likely to detach from the interlock structure. Therefore, the failure of the clinched structures in the PHA group occurred almost simultaneously with the failure of the adhesive layer, and there was no secondary rebound of the 
load.

The other failure mode of the PHA group is referred to as upper sheet tearing in this paper. Its load-displacement curve presented two maximum points. The load reached the first maximum point with increasing displacement before the adhesive layer failed. When the adhesive layer failed, the mechanical interlock strength, provided by the clinched structure, was larger than the increasing peeling force. The T-joint specimen developed obvious plastic deformation, and the angle of the T-bending gradually changed from $90^{\circ}$ to almost straight. While that was taking place, the load of the PHA group exhibited a smooth recovery, until reaching maximum peeling strength, which is the second maximum point on the load-displacement curve. Here, the clinched neck near the T-bending tore, and the joint load began to decrease. When the neck material tore in half, the upper sheet experienced lateral tearing from the peeling force, whose direction was perpendicular to the clinched surface. The upper sheet gradually peeled until complete separation from the lower sheet occurred, and the load immediately dropped to zero.

Fig.13(b) shows the peeling process of the PHS group. Due to the good mechanical interlock structure and weak neck bearing, the failure of the PHS group is consistent with the second failure mode of the PHA group, upper sheet tearing. The peeling strength reached the first peak at adhesive failure, and the T-bending angle of the specimen changed from $90^{\circ}$ to almost straight, resulting in load recovery to the maximum peeling strength. The weakest part of neck tore in half, and turned laterally until separation.

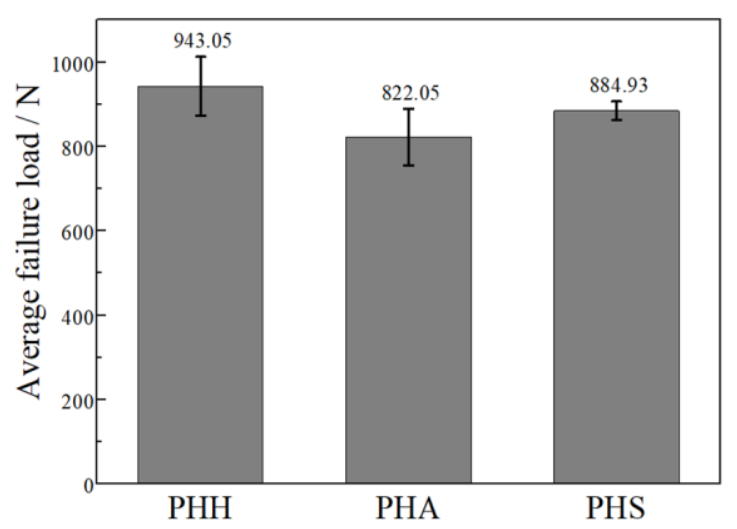

(a) Failure load of three groups

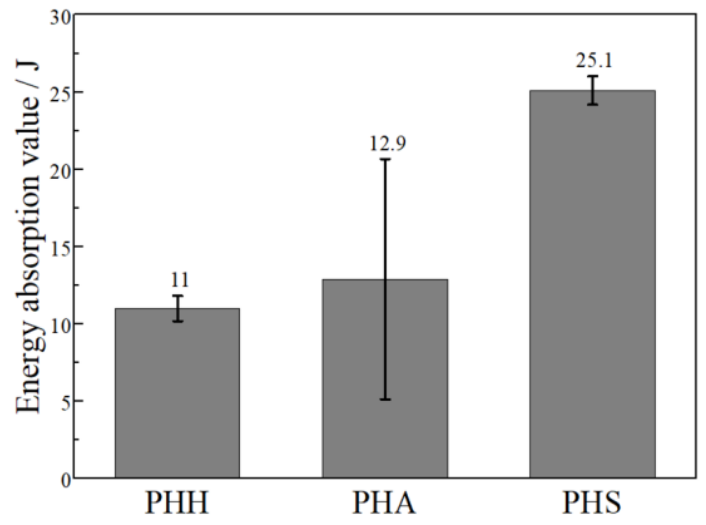

(b) Energy absorption value of three groups

Fig. 14. Result of peeling test for different T-joints

Fig. 14(a) shows a comparison of the mean failure load of the three groups of T-joints, and Fig. 14(b) shows the energy absorption values. The maximum average peeling strength of the PHH group is $943.05 \mathrm{~N}$, but its poor displacement with bottom separation failure results in the lowest energy absorption value, and the worst joint buffer ability of the three groups. For the PHA group, the mean peeling strength is $822.05 \mathrm{~N}$, and energy absorption value is between the other two because of two 
different failure modes. The peeling strength of the PHS group is $884.93 \mathrm{~N}$, which benefited from a good mechanical interlock structure, its changes in bending angle and the long tensile displacement, all of which all led to the excellent energy absorption ability of the PHS group.

In conclusion, the best energy absorption ability can be achieved by the upper sheet tearing failure mode. Improving the strength of the lower sheet, to obtain greater joint peeling strength, can be found in the clinch-bonded hybrid joint.

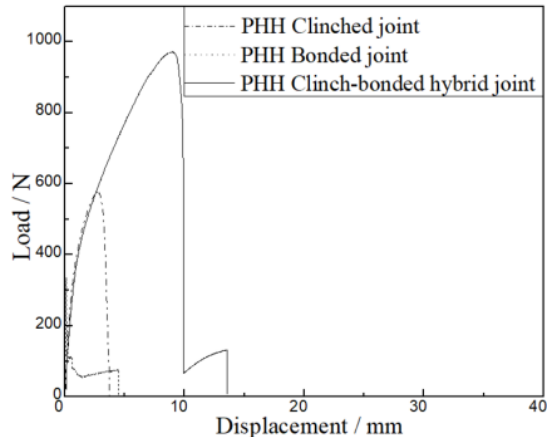

(a) $\mathrm{PHH}$

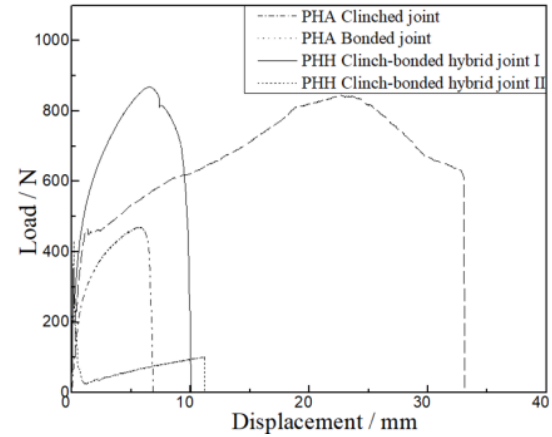

(b) PHA

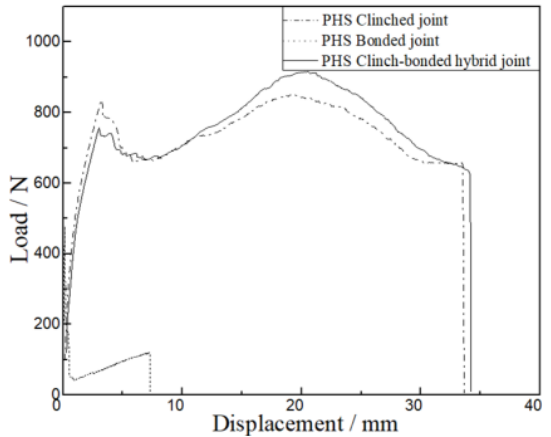

(c) PHS

Fig. 15. Load-displacement curves of clinched joint, bonded joint and clinch-bonded joint

As shown in Fig.15, the load-displacement curves of PHH, PHA and PHS for clinched joint, bonded joint and clinch-bonded hybrid joint are presented. Because the peeling force is perpendicular to the connection surface, bonded joint failed with low peeling strength and a short time as a result of face-face contact. However, clinching benefits from the clinched structure to obtain rich change trends under peeling force. For the clinch-bonded hybrid joining, its load-displacement curves are similar to clinching, adhesive has almost no effect on hybrid joint due to quick adhesion failure.

According to the analysis of the peeling test results, the failure modes of the PHA group are similar to both the PHH and PHS groups. Two types of typical failure fractures of the PHH and PHS groups were studied by a SEM to analyse their failure mechanisms, and the results are shown in Figs 16 and 17.

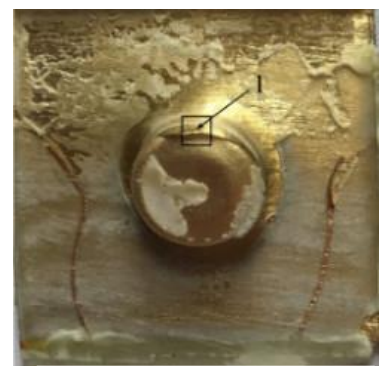

(a) Macroscopic profile

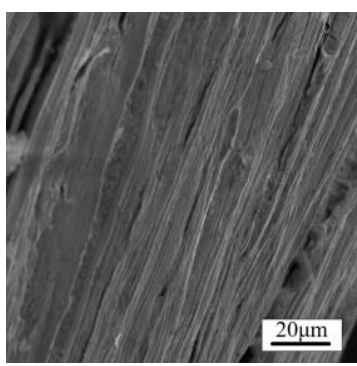

(b) Microcosmic profile in area 1

Fig. 16. Scratching of upper sheet of PHH joint 
The macroscopic and microscopic profiles of the PHH group after button separation, with slight scratching evident, are shown in Fig. 13. It can be seen that the clinched structure is intact, but scratching is present in area 1 , where a mass of thin ridges with a high-density distribution formed the rough surface. The surface structure density of area 1 is high, which shows that this area bore mainly relatively large compression forces, and the direction was consistent with the ridge directions shown in Fig. 13(b).

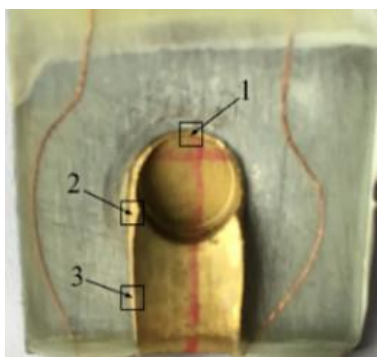

(a) Macroscopic profile

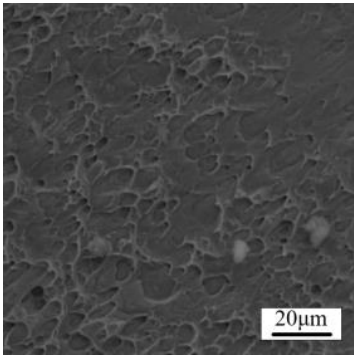

(b) Microcosmic profile in area 1

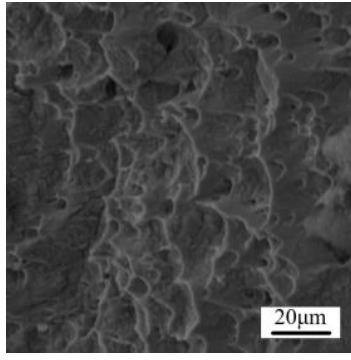

(c) Microcosmic profile in area 2

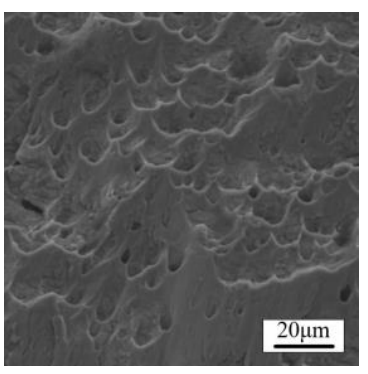

(d) Microcosmic profile in area 3

Fig.17. Tear fracture of upper sheet of PHS joint

Fig. 17 shows the three areas of upper sheet tearing fracture of the PHS group. In Fig. 17(b), it can be seen that a large number of tearing ridges, which are short, curved, and distributed in a highly dense manner, are shown as small river patterns, and some micropores and the second phase of inclusion also appeared on the surface. Area 1 presents quasi-cleavage fracture characteristics. The microscopic profile of area 2 is shown in Fig. 17(b), where the whole surface is uneven, and the fracture presents many large and deep elongated dimples, surrounded by some small dimples and huge voids; the direction of the dimples is coaxial and approximately perpendicular to the fracture plane. Area 2 could absorb more energy because of larger and deeper damage than the other areas, which is typical of ductile fracture. The microscopic plastic deformation of area 3 is small, and shows a 'step shape' of layered fracture. At the same time, the edge of the step appeared as shallow ' $U$ ' shapes, and the wave-shape elongated dimples and their direction were the same as the direction of the upper sheet tearing. Area 3 has mixed fractures of dissociation, and minor ductile fracture characteristics.

\subsection{Comparison of single-lap joints and T-joints}

The typical load-displacement curves, and the energy absorption values of the single-lap joints and T-joints about clinch-bonded hybrid joining are shown in Fig. 18.

It can be seen from Fig. 18 that the shear strength in single-lap joints is higher than the peeling strength in T-joints for the same material combinations. From the tensile-shear tests, the adhesives developed maximum shear strength before shear failure occurred, and they played a more important role in the shear strength of joints than clinched structures. However, clinched structures were stronger in the peeling tests, and the adhesive layer worked short time, as the direction of the tensile 
force was perpendicular to adhesive plane.

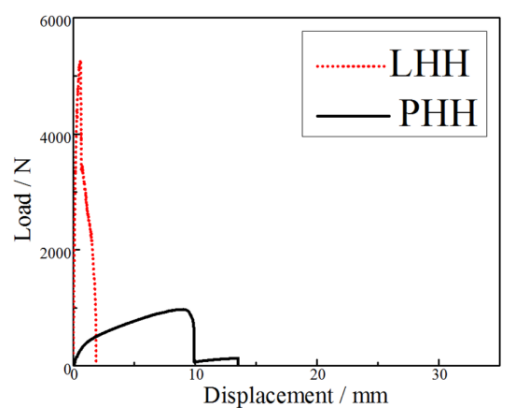

(a) H62-H62

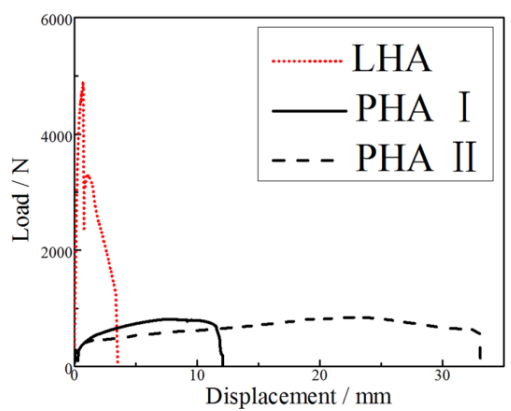

(b) H62-A15052

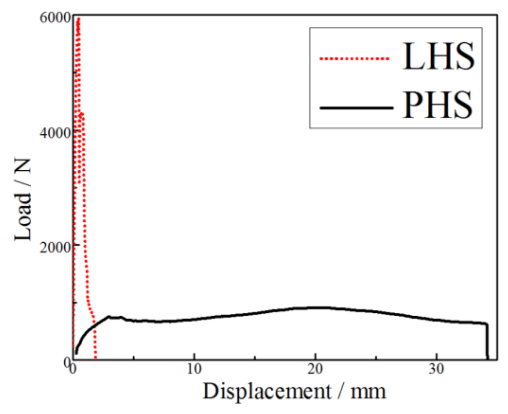

(c) H62-Galvanised steel

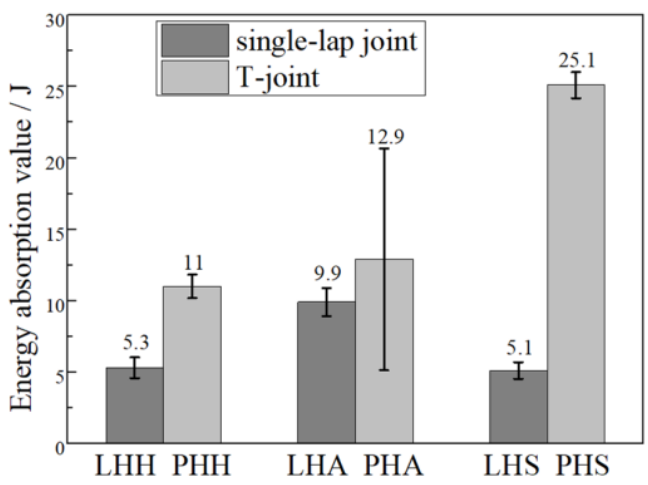

(d) Energy absorption value of six groups

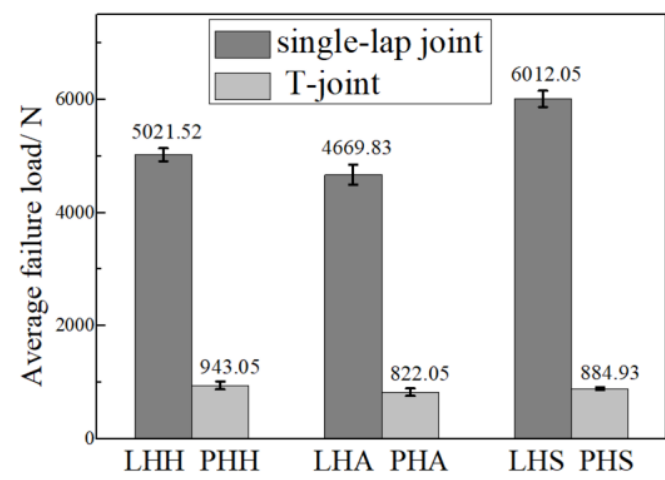

(e) Average failure load of six groups

Fig. 18. Comparison of load-displacement curves and average absorption value of different joints

From Fig. 18(d), it is obvious that the energy absorption ability of T-joints is better than that of single-lap joints. This is because the T-bending specimens absorbed more plastic deformation when their angles changed from $90^{\circ}$ to near zero, when loaded in the direction of the T-shape. The necks of clinched structures are more susceptible to laterally tearing under forces perpendicular to the joining plane. These all resulted in an increase of tensile displacement, and an improved energy absorption ability.

\section{Conclusions}

In this study, three groups' specimens, H62-H62, H62-A15052, and H62-galvanised steel, were prepared for clinch-bonded hybrid jointing tests. Two series of tests, single-lap joints for tensile-shear testing and T-joints for peeling testing, were carried out using an MTS Landmark Servo-hydraulic Test System, and failure fractures were studied to analysis failure loads, energy absorption values, and failure modes, to characterise mechanical properties of different joints. The results showed that:

1) The shear strength of clinch-bonded hybrid joints is better than its peeling strength.

2) In clinch-bonded hybrid joining, the shear strength results mainly from the adhesive, while 
the peeling strength is provided by the clinched structure.

3) The mixed neck fracture has the best shear strength, and a better ability to absorb energy can be attained by decreasing the material strength of the lower sheet in tensile-shear tests.

4) The best energy absorption ability can be obtained by the failure mode of upper sheet tearing in the peeling test. Improvement of the strength of the lower sheet for increased joint peeling strength was found.

\section{Acknowledgement}

This study is supported by the National Natural Science Foundation of China (Grant No. 51565023) and Major Program Foundation of the Education Department of Yunnan Province, China (Grant No. ZD201504).

\section{References}

[1] D Cui, L Zhang, K Mylvaganam, W Liu, W Xu, Nano-milling on monocrystalline copper: a molecular dynamics simulation, Mach. Sci. Technol. 21 (1) (2017) 67-85.

[2] D Stanley, J Awerbuch, TM Tan, Reconstruction of fatigue crack growth in aluminum lithium and aluminum copper fastened lap joints under marker band loading, Int. J. Fatigue. 103 (2017) $516-532$.

[3] Y Tokita, T Nakagaito, Y Tamai, T Urabe, Stretch formability of high strength steel sheets in warm forming, J. Mater. Process. Technol. 246 (660) (2017) 77-84.

[4] L Zhao, X He, B Xing, X Zhang, Q Cheng, F Gu, A Ball, Fretting behavior of self-piercing riveted joints in titanium sheet materials, J. Mater. Process. Technol. 249 (2017) 246-254.

[5] X He, Influence of boundary conditions on stress distributions in a single-lap adhesively bonded joint, Int. J. Adhes. Adhes. 53 (3) (2014) 34-43.

[6] MM Eshtayeh, M Hrairi, Recent and future development of the application of finite element analysis in clinching process, Int. J. Adv. Manuf. Technol. 84 (9-12) (2016) 2589-2608.

[7] MM Eshtayeh, M Hrairi, Multi objective optimization of clinching joints quality using Grey-based Taguchi method, Int. J. Adv. Manuf. Technol. 87 (1-4) (2016) 233-249.

[8] X He, L Lei, Y Zhang, B Xing, Mechanical properties and fracture analysis of clinched joints in titanium sheet materials, Acta Phys. Pol. 131 (1) (2017) 16-19.

[9] J Varis, The suitability of round clinching tools for high strength structural steel, Thin-Walled Struct. 40(3) (2002) 225-238.

[10] J Varis, Ensuring the integrity in clinching process, J. Materi. Process. Technol. 174 (1-3) (2006) 
277-285.

[11] M Oudjene, L Ben-Ayed, On the parametrical study of clinch joining of metallic sheets using the taguchi method, Eng. Struct. 30 (6) (2008) 1782-1788.

[12] M Oudjene, L Ben-Ayed, A Delamézière, JL Batoz, Shape optimization of clinching tools using the response surface methodology with moving least-square approximation, J. Mater. Process. Technol. 209 (1) (2009) 289-296.

[13] AAD Paula, MTP Aguilar, AEM Pertence, PR Cetlin, Finite element simulations of the clinch joining of metallic sheets, J. Mater. Process. Technol. 182 (1) (2007) 352-357.

[14] CJ Lee, JY Kim, SK Lee, DC Ko, BM Kim, Design of mechanical clinching tools for joining of aluminium alloy sheets, Mater. Des. 31 (4) (2010) 1854-1861.

[15] CJ Lee, JY Kim, SK Lee, DC Ko, BM Kim, Parametric study on mechanical clinching process for joining aluminum alloy and high-strength steel sheets, J. Mech. Sci. Technol. 24 (1) (2010) 123-126.

[16] J Mucha, L Kaščák, E Spišák, Joining the car-body sheets using clinching process with various thickness and mechanical property arrangements, Arch. Civ. Mech. Eng. 11 (1) (2011) 135-148.

[17] J Mucha, W Witkowski, The clinching joints strength analysis in the aspects of changes in the forming technology and load conditions, Thin-Walled Struct. 82 (82) (2014) 55-66.

[18] J Mucha, W Witkowski, The experimental analysis of the double joint type change effect on the joint destruction process in uniaxial shearing test, Thin-Walled Struct. 66 (2013) 39-49.

[19] L Kaščák, E Spišák, R Kubik, J Mucha, FEM analysis of clinching tool load in a joint of dual-phase steels, Strength. Mater. 48 (4) (2016) 533-539.

[20] M Hiller, T Benkert, S Vitzthum, W Volk, Influence of tool elasticity on process forces and joint properties during clinching with rotational tool movement, J. Phys. 896 (1) (2017) 012116.

[21] A Breda, S Coppieters, D Debruyne, Equivalent modelling strategy for a clinched joint using a simple calibration method, Thin-Walled Struct. 113 (2017) 1-12.

[22] L Kaš čák, J Mucha, E Spišák, R Kubik, Wear Study of Mechanical Clinching Dies During Joining of Advanced High-Strength Steel Sheets, Strength of Materials. 49 (5) (2017) 726-737.

[23] H Krzton, J Mucha, W Witkowski, The application of laboratory X-ray micro-diffraction to study the effects of clinching process in steel sheets, Acta Phys. Pol. 130 (4) (2016) 985-987.

[24] M K S Atia, M K Jain, Die-less clinching process and joint strength of AA7075 aluminum joints, Thin-Walled Struct. 120 (2017) 421-431.

[25] S Coppieters, P Lava, S Baes, H Sol, P V Houtte, D Debruyne, Analytical method to predict the pull-out strength of clinched connections, Thin-Walled Struct. 52 (2012) 42-52. 
[26] HK Kim, Fatigue strength evaluation of the clinched lap joints of a cold rolled mild steel sheet, J. Mater. Eng. Perform. 22 (1) (2013) 294-299.

[27] K Mori, Y Abe, T Kato, Mechanism of superiority of fatigue strength for aluminium alloy sheets joined by mechanical clinching and self-pierce riveting, J. Mater. Process. Technol. 212 (9) (2012) 1900-1905.

[28] Y Abe, K Mori, T Kato, Joining of high strength steel and aluminium alloy sheets by clinching with dies for control of metal flow, J. Mater. Process. Technol. 212 (2012) 884-889.

[29] F Lambiase, Influence of process parameters in mechanical clinching with extensible dies, Int. J. Adv. Manuf. Technol. 66 (9-12) (2013) 2123-2131.

[30] F Lambiase, AD Ilio, Finite element analysis of material flow in mechanical clinching with extensible dies, J. Mater. Eng. Perform. 22 (6) (2013) 1629-1636.

[31] F Lambiase, AD Ilio, A Paoletti, Joining aluminium alloys with reduced ductility by mechanical clinching, Int. J. Adv. Manuf. Technol. 77 (5-8) (2015) 1295-1304.

[32] F Lambiase, A Dillio, An experimental study on clinched joints realized with different dies, Thin-Walled Struct. 85 (2014) 71-80.

[33] V Jayasekara, KH Min, JH Noh, TK Min, JM Seo, HY Lee, BB Hwang, Rigid-plastic and elastic-plastic finite element analysis on the clinching joint process of thin metal sheets, Met. Mater. Int. 16 (2) (2010) 339-347.

[34] C Chen, S Zhao, X Han, M Cui, S Fan, Optimization of a reshaping rivet to reduce the protrusion height and increase the strength of clinched joints, J. Mater. Process. Technol. 234 (2016) 1-9.

[35] C Chen, S Zhao, X Han, M Cui, S Fan, Investigation of the height-reducing method for clinched joint with Al5052 and Al6061, Int. J. Adv. Manuf. Technol. 89 (5-8) (2016) 1-8.

[36] C Chen, S Zhao, X Han, M Cui, X Zhao, T Ishida, Experimental investigation of the mechanical reshaping process for joining aluminum alloy sheets with different thicknesses, J. Manuf. Process. 26 (2017) 105-112.

[37] C Chen, S Zhao, X Han, M Cui, S Fan, Investigation of mechanical behavior of the reshaped joints realized with different reshaping forces, Thin-Walled Struct. 107 (2016) 266-273.

[38] C Chen, X Han, S Zhao, F Xu, X Zhao, Comparative study on two compressing methods of clinched joints with dissimilar aluminum alloy sheets, Int. J. Adv. Manuf. Technol. 93 (5-8) (2017) 1929-1937.

[39] C Chen, S Zhao, M Cui, X Han, S Fan, T Ishida, An experimental study on the compressing process for joining Al6061 sheets, Thin-Walled Struct. 108 (2016) 56-63.

[40] IU Ojalvo, HL Eidinoff, Bond thickness effects upon stresses in single-lap adhesive joints, Aiaa 
J 16 (3) (1977) 204-211.

[41] MJL Van Tooren, LA Krakers, A generalized stress singularity approach for material failure prediction and its application to adhesive joint strength analysis, J. Adhes. Sci. Technol. 20 (9) (2006) 981-995.

[42] MK Apalak, M Ekici, M Yildirim, Free vibration analysis and design of an adhesively bonded corner joint with double support, J. Adhes. 83 (11) (2007) 957-986.

[43] X He, Numerical and experimental investigations of the dynamic response of bonded beams with a single-lap joint, Int. J. Adhes. Adhes. 37 (2012) 79-85.

[44] X He, Finite element analysis of torsional free vibration of adhesively bonded single-lap joints, Int. J. Adhes. Adhes. 48 (1) (2014) 59-66.

[45] X He, SO Oyadiji, Influence of adhesive characteristics on the transverse free vibration of single lap jointed cantilevered beams, J. Mater. Process. Technol. 119 (2001) 366-373.

[46] F Moroni, A Pirondi, F Kleiner, Experimental analysis and comparison of the strength of simple and hybrid structural joints, Int. J. Adhes. Adhes. 30 (5) (2010) 367-379.

[47] X He, F Liu, B Xing, H Yang, Y Wang, F Gu, A Ball, Numerical and experimental investigations of extensible die clinching, Int. J. Adv. Manuf. Technol. 74 (2014) 1229-1236.

[48] $\mathrm{T}$ Balawender, $\mathrm{T}$ Sadowski, $\mathrm{P}$ Golewski, Numerical analysis and experiments of the clinch-bonded joint subjected to uniaxial tension, Comp. Mater. Sci. 64 (2012) 270-272.

[49] CJ Lee, JM Lee, KH Lee, DH Kim, HY Ryu, BM Kim, Development of hybrid clinched structure by using multi-cohesive zone models, Int. J. Precis. Eng. Manuf. 15 (6) (2014) 1015-1022.

[50] J Chen, Z Qiu, Y Zhou, F Lan, Performances of clinch-bonded hybrid joints between steel-aluminum sheets, J. Harbin Inst. Technol. 48 (7) (2016) 169-175, (in Chinese).

[51] X He, Clinching for sheet materials, Sci. Technol. Adv. Mater. 18 (1) (2017) 381-405.

[52] J H Kweon, J W Jung, T H Kim, J H Choi, D H Kim, Failure of carbon composite-to-aluminum joints with combined mechanical fastening and adhesive bonding, Comp. Struct. 75 (1-40) (2006) 192-198. 